\title{
O ideal de beleza numa sociedade desigual: notas sobre a opressão ao corpo feminino em tempos de pandemia*
}

\author{
Maria Laís dos Santos Leite**
}

\begin{abstract}
Dias e semanas de quarentena se passam, para umas/uns mais rápido, para outras(os) como torturantes dias sem fim, iguais, grises. Certezas de nossa sociedade - local de trabalho, compromissos presenciais, eventos acadêmicos, necessidades de consumo - caem por terra, diante de um vírus do qual sabemos pouco e que revirou nosso cotidiano, nos fez desmarcar viagens, recriar rotinas de trabalho. Pedimos/nos pedem para nos cuidar, parar e como lema máximo: ficar em casa! ${ }^{1}$ - para umas/uns uma missão impossível, para outras(os) a percepção de estarem aprisionadas(os), para outras(os) uma possibilidade de manter-se protegidas(os). As ações corriqueiras e o que chamávamos de cotidiano já não existe, por mais que tantas(os) ainda tentem simular uma realidade ou negar os efeitos da Covid-19 em nossas vidas.

Tantas percepções destas desigualdades de nosso sistema-mundo capitalista, ocidental, misógino e racista ${ }^{2}$ caberiam aqui, mas falaremos de uma problemática cujas análises se aprofundaram pela leitura do livro resenhado: o controle sob o corpo feminino. Como há anos não me ocorria, volto a minha 'estante virtual' - com mais livros do que conseguirei ler nos próximos anos - não procurando o que preciso agora, mas com a sensação de que posso ler algo que não precisa ser útil para um novo projeto, para um novo artigo - já viram que não deu certo, maldito capitalismo acadêmico! -. Na lista de livros para ler, havia um que iniciei a leitura no ano passado, O Mito da Beleza: como as imagens de beleza são usadas contra as mulheres, a obra de Naomi Wolf escrita no contexto de outrora, era lido agora sob o prisma da pandemia que estamos vivenciando.

A autora nascida em San Francisco na Califórnia em 1962, doutora em Filosofia pela Universidade de Oxford se apresenta em seu LinkedIn ${ }^{3}$ como uma escritora de não ficção que escreveu oito best-sellers internacionais, a maioria deles sobre questões femininas ou sobre liberdades civis e democracia.

O livro foi publicado originalmente em língua inglesa em 1991 e relançado no Brasil 2018 com uma lista de pré-textuais que o atualizam e revitalizam. É composto por oito partes: I. O mito da beleza; II. O trabalho; III. A cultura; IV. A religião. V. O sexo; VI. A fome; VII. A violência e VIII. Para além do mito da beleza.
\end{abstract}

\footnotetext{
* Recebida em 01 de junho de 2020, aceita em 30 de outubro de 2020. Resenha do livro: WOLF, Naomi. O Mito da Beleza: como as imagens de beleza são usadas contra as mulheres. Rio de Janeiro, Rosa dos Tempos, 2018 [Edição do Kindle].

** Doutoranda em Psicologia pela Universidade Federal do Rio Grande do Norte - UFRN. Servidora técnico-administrativa da Universidade Federal do Cariri (UFCA), coordenadora do Laboratório de Estudos em Políticas Públicas do Cariri LEPP Cariri, Juazeiro do Norte, CE, Brasil.) mlaisleite@gmail.com/ http://orcid.org/0000-0001-5777-3205

1 Salienta-se que a indicação de "ficar em casa", especialmente nos meses de março a maio de 2020 em que escrevemos este texto, tem impactos distintos para famílias de diferentes camadas da população, já que para "as populações de baixa renda que têm pouco acesso aos cuidados de saúde e necessitam escolher entre ficar em casa e passar fome ou correr os riscos do descumprimento ao isolamento para o sustento de si e da família" (Estrela et al., 2020).

2 Corroboramos aqui com posicionamentos e compreensões interseccionais para compreender as questões de gênero no sistema-mundo capitalista diretamente relacionadas aos marcadores de raça, classe e território. Sobre este assunto recomendamos a leitura de Moutinho (2016).
}

${ }^{3}$ [ https://www.linkedin.com/in/dr-naomi-wolf-324460b4/]. 
Para Wolf (2018), o livro em sua publicação original obteve sucesso por apresentar uma argumentação no "exato momento em que uma geração de mulheres jovens queria de fato adotar uma nova versão do feminismo, queria de fato analisar as condições singulares que as cercavam $e$ levar a sério a própria opressão que as atingia" (n.p.).

Comprado por indicação para a composição de um estudo sobre os feminismos, O Mito da Beleza parecia falar do apelo às cirurgias plásticas, moda, maquiagem questões que, naquele momento, talvez não me convocassem tanto. Inclusive pela negação de que essa pauta seria relevante para o avanço dos feminismos. Aprendi que não, que esta discussão não está superada, mas presente de forma patente em nossas conversas informais com amigas, com a Mãe, ainda mais insistentemente na televisão, nos tutoriais do YouTube e nos perfis premiados do Instagram $e$ Tiktok.

Percebi que estava errada - e talvez esse seja o motivo que me fez escrever esta resenha -, precisamos ouvir a Naomi Wolf, precisamos tirar da estante as discussões que deslocam nossas percepções que nos fazem sair da zona de conforto. Ademais, ponderei que de tanto defender os feminismos subalternos, pós-coloniais, decoloniais e negros eu também podia incorrer no mesmo exclusivismo que tão duramente criticamos. Percebi que necessitava saber mais sobre a realidade de outras mulheres, inclusive as brancas, urbanas, ricas, estadunidenses para as quais a gente, com o dedo em riste, aponta que "não sofreu tanto assim".

A escritora já me leva ao repensar, ao reconhecer que "os novos feminismos são muito diferentes do feminismo icônico das décadas de 1960 e 1970' por serem mais "pluralistas, mais tolerantes, mais inclusivos aos homens, mais conscientes de questões relacionadas aos movimentos LGBT" (Wolf, 2018, n.p, grifos meus).

Outro avanço relevante no feminismo atual, pontuado pela autora, é a discussão da interseccionalidade. Wolf (2018) a ressalta quando afirma que o movimento está mais atento e avançado na relevância na "interseção de raça, classe e gênero, mais atentos para as questóes feministas no mundo em desenvolvimento" (n.p, grifos meus).

Questionei tanto os feminismos liberais/igualitários/universalistas por considerá-los excludentes ao negar a realidade daquelas que não estavam no ocidente, e que não eram consideradas dignas de proteção e muito menos proibidas de trabalhar, que percebi que havia deixado "umas manas" pelo caminho, que o ranço ao "white people problem", havia me afastado de um problema que eu achava que não era meu, de corpos que se submetem à intervenções cirúrgicas ou a indústria da beleza após um acúmulo de não-aceitação, de autoimagens moldadas diante das pressões sociais que devem agradar não a quem 'os habitam', mas aos que o veem, como se repetiu até a exaustão no hit do carnaval no Brasil de 2020.

$\mathrm{Na} 16^{\mathrm{a}}$ página já havia me dado conta que precisava aprender sobre isso e saber mais sobre uma temática que causa sofrimento para tantas mulheres, inclusive para mim. Já não apenas ignorava os conteúdos que me chegavam e que pareciam agora me incomodar, fingindo que eles haviam sido encaminhados para a mulher errada que, agora, no meio da sensibilidade exacerbada pela pandemia e inquieta por Wolf (2018), já esconjurava: precisamos problematizar este ideal de mulher bonita, precisamos pensar sobre os nossos corpos e o que tem sido imposto e cobrado dele em nome de um ideal inatingível de beleza!

Naomi Wolf (2018) "me falava" das mulheres ganhando as ruas, no início dos anos 70, das conquistas obtidas após as décadas posteriores ao renascimento do feminismo em que "as mulheres ocidentais conquistaram direitos legais e de controle de reprodução, alcançaram a educação superior, entraram para o mundo dos negócios e das profissões liberais e derrubaram crenças antigas e respeitadas quanto ao seu papel social" (n. p.).

Seguindo dessa retomada, a autora perguntava se, uma geração depois, nos sentíamos livres. Para ela "as mulheres prósperas, instruídas e liberadas do Primeiro Mundo, que têm acesso a liberdades inatingíveis para qualquer outra mulher até agora, não se sentem tão livres quanto querem ser" (Wolf, 2018, n.p.).

No livro, objeto desta análise, Wolf (2018) explica ainda que muitas mulheres "sentem vergonha de admitir que essas preocupaçôes triviais - que se relacionam à aparência física, ao corpo, ao rosto, ao cabelo, às roupas - têm tanta importância." (n.p., grifo meu). Mas apesar dos 
sentimentos de vergonha, culpa e negação, têm sofrido com a gordofobia, a pressão estética e/ou body shaming.

Não Wolf, apesar de não obter uma alta pontuação na lista de privilégios que você nomeou, não me sinto tão livre assim, eu e outras mulheres continuamos sendo impelidas a cuidar mais da aparência física do que os homens, sejam eles nossos irmãos, companheiros, colegas, chefes. A cada página lida, refletia sobre as postagens que via nas redes sociais em contas pessoais $e$ organizacionais com dicas de como manter as unhas bonitas, de como se divertir, de como cuidar das crianças, de como manter o cabelo hidratado, de makes e looks para home office - assim mesmo com muito termos em inglês que "o povo" gosta -, dicas do que comer, memes gordofóbicos e vídeos supostamente cômicos retratam a preocupação das pessoas em manter as regras de dieta e exercício físico para não perder a "boa forma" ou o controle - que se manifesta mantendo o corpo no padrão socialmente aceito - durante a pandemia.

$\mathrm{O}$ que essas publicações têm em comum? Se mantém o apelo a dominação dos corpos, a dominação do corpo feminino, que precisa ser ou se manter magro, com cabelos e unhas performaticamente preparados para serem considerados belos. Afinal, já nos dizia Wolf (2018): "quanto mais numerosos foram os obstáculos legais e materiais vencidos pelas mulheres, mais rígidas, pesadas e cruéis foram as imagens da beleza feminina a nós impostas" (n.p., grifo nosso).

Por mais que talvez tenhamos agora uma exposição de corpos diversos, de atrizes, cantoras, "youtubers" e "influencers" gordas, magras, negras, brancas, pardas, com traços indígenas, não consigo acreditar que já tivemos mais gente observando, opinando, regulando e oprimindo nossos corpos, chegando a constranger e agredir pessoas anônimas e artistas ao criticar suas formas físicas em suas redes sociais.

Wolf (2018), nos aponta que na conjuntura que vivemos seja mais comum que revistas $e$ personalidades reflitam acerca da "[...] a artificialidade e o impacto psicológico negativo dessas ideias; e é mais comum que as próprias mulheres procurem estabelecer meios para resgatar seu próprio corpo e sua própria beleza segundo formas que elas mesmas definem" (n.p.).

A autora assevera ainda que "editores de revistas femininas também tentam destacar imagens mais inclusivas, embora continuem sob a forte pressão dos anunciantes" (Wolf, 2018, n.p.). Wolf (2018) ressalta também o papel das mídias sociais nos avanços obtidos ao buscar pluralizar os ideais de beleza e visibilizar corpos até então distantes do reconhecimento e dos veículos de comunicação "apesar de haver quem diga que elas intensificam a pressão sobre as jovens para se sentirem inseguras quanto ao físico - também derrubam a barreira entre o consumidor e o produtor da mídia" (n.p., grifo nosso).

A autora fala do cenário da década de 90, nos Estados Unidos, mas tal apresentação nos parece tão atual e acirrada em tempos de avanço de conservadorismo no Brasil de 30 anos depois, "o feminismo tinha se tornado um palavrão" (Wolf, 2018, n.p.).

Outrora - e agora - se procurava buscar qual a "inadequação" das mulheres para levantar a bandeira dos feminismos, sendo comum o recurso desqualificador de adjetivar as mulheres "que reclamavam do mito da beleza tinham, elas sim, algum defeito: provavelmente eram gordas, feias, incapazes de satisfazer um homem, 'feminazis', ou - horror dos horrores - lésbicas" (Wolf, 2018, n.p.).

O papel da mídia de massa, todavia, não pode ser desconsiderado e tem buscado manter o ideal de beleza a figura de "uma caucasiana cadavérica, mas com seios generosos, raramente encontrada na natureza - era eterno, transcendente. Parecia ter uma importância acima de qualquer questionamento tentar de algum modo estar à altura daquele ideal" (Wolf, 2018, n.p.).

Outro ponto relevante abordado por Wolf (2018) era a influência da pornografia na moda $e$ na percepção das mulheres de seus próprios corpos, já que por causa da "recente influência da pornografia na moda, milhões de mulheres de repente estavam vendo 'os seios perfeitos' por toda parte e, consequentemente, começaram a se preocupar com seus seios naturalmente "imperfeitos'". (n.p).

Pena que não fomos tão longe, muitas(os) de nós, inclusive que se dizem feministas $e$ militantes LGBTs, ainda não se deram conta dos danos psicossociais do compartilhamento de imagens que tentam trazer como elementos cômicos os corpos femininos, cujas formas não são 
consideradas satisfatórias pela sociedade do controle. Poucas(os) ainda são as(os) que compreendem os riscos - inclusive psicológicos - a que estão expostas(os) as(os) que se submetem às cirurgias plásticas e outros métodos mais ou menos invasivos de harmonização de rostos $e$ "remodelação" de corpos.

Para as(os) que gostam de dados econômicos, como eu, pode-se surpreender com a cifras às quais Wolf (2018) faz referência, circunscrevendo a indústria da beleza como uma das mais rentáveis, movimentando bilhões de reais por ano, boa parte deles no nosso desigual país. Entres essas, destacamos as indústrias das "[...] dietas, que gera US\$33 bilhões por ano; a dos cosméticos, US\$ 20 bilhões; a da cirurgia plástica estética, US\$ 300 milhões; e a da pornografia, com seus US\$ 7 bilhões" (Wolf, 2018, n.p.).

Como a autora nos exorta: "O mito da beleza, como muitas ideologias da feminilidade, muda para se adaptar a novas circunstâncias e põe em xeque o esforço que as mulheres fazem para aumentar seu próprio poder" (Wolf, 2018, n.p., grifos meus). Inclusive das que se entendem que são "desconstruídas", ilesas da pressão estética.

Parece-me agora que esta discussão não está tão longe assim, e chega de modos diferentes à todas nós, "agora que estamos mais fortes sob o aspecto material, o mito da beleza, na forma em que ressurgiu na última geração, teve de recorrer a sofisticação tecnológica e fervor reacionário maiores do que anteriormente" (n.p., grifos meus).

Atualmente, o mito da beleza "[...] atende ao chamado do temor político por parte de instituições dominadas pelos homens, instituições ameaçadas pela liberdade das mulheres [...] explora a culpa e a apreensão quanto a nossa própria liberação" (Wolf, 2018, n.p., grifos meus).

Indico a obra $O$ Mito da Beleza para pessoas de todos os gêneros e orientações sexuais, acadêmica(os) ou não, com a expectativa de que esta obra que permanece atual amplie nossa percepção da pressão estética, da gordofobia e a opressão ao corpo feminino, ainda mais recorrentes, neste momento de pandemia. Precisamos ouvir as feministas, todas elas, das diferentes gerações, raças/etnias, classes sociais, contextos territoriais, religiões, afinal, como nos aponta Audre Lorde (2007:132) numa das mais célebres frases feministas: "Não sou livre enquanto outra mulher for prisioneira, mesmo que as correntes dela sejam diferentes das minhas".

\section{Referências bibliográficas}

ESTRELA, Fernanda Matheus et al. Pandemia da Covid 19: refletindo as vulnerabilidades a luz do gênero, raça e classe. Ciência \& Saúde Coletiva [online], v. 25, n. 9, 2020, pp.3431-3436. Epub 28 Ago 2020. ISSN 1678-4561. [https://doi.org/10.1590/1413-81232020259.14052020 - acesso em: 4 jul. 2021].

LORDE, A. Sister outsider. essays and speeches. Berkeley, Crossing Press, 2007.

MOUTINHO, Laura. Diferenças e desigualdades negociadas: raça, sexualidade e gênero em produções acadêmicas recentes. cadernos pagu (42), Campinas, SP, 2016, $\quad$ pp.201-248 [https://periodicos.sbu.unicamp.br/ojs/index.php/cadpagu/article/view/8645121 - acesso em: 1 jul. 2021].

WOLF, Naomi. O Mito da Beleza: como as imagens de beleza são usadas contra as mulheres. Rio de Janeiro, Rosa dos Tempos, 2018. [Edição do Kindle]. 